DOI: $10.20472 /$ IAC.2019.047.028

\title{
NOZOMI TANAKA
}

Tokai Gauen University, Japan

\section{KATSUNORI FUJII}

Graduate school of Business Administration and Computer Science, Aichi Institute of Technology, Japan

\section{TOSHIRO SAKAI}

Chubu University, Japan

\author{
YUKI KANI
}

Graduate school of Business Administration and Computer Science, Aichi Institute of Technology, Japan

\section{ISSUES IN PHYSICAL FITNESS OF CONTEMPORARY JAPANESE BOYS JUDGED WITH EVALUATION CRITERIA FOR THE PAST}

\begin{abstract}
:
In this study, evaluation criteria for physique and physical fitness in early childhood were constructed with consideration of age-related changes. The wavelet interpolation model was used for data from young children in 1979, when physical fitness was at a high level in postwar Japan. This evaluation chart was then used to investigate the kinds of problems that could be indicated in the physical development of young children today, by evaluating their physique and physical fitness. Physical fitness was evaluated in 2,014 boys in Aichi Prefecture, Japan. Height, weight, $20 \mathrm{~m}$ dash, standing long jump, and tennis ball throw were measured from April to June, 2009. In constructing evaluation criteria for the past, data collected in 1979 for the same items as above were used. The subjects were 2,397 boys in Aichi Prefecture. An age-related change curve with a 5-step evaluation by age was drawn for the collected measurement data using the wavelet interpolation model, and an evaluation chart was constructed. The results showed that height was shorter at 3 years of age in 2009 than in 1979, but that later there was a tendency for height to catch up with that in 1979 with age. It is conjectured that this shows a faster maturation speed in boys compared with 30 years ago. There was more scattering in the lower level of the running and jumping ability aspects of physical fitness, while in throwing ability the level was obviously low at all ages. The results of this study indicate that issues related to the growth and development of young children today are underdevelopment in relation to the continuous display of leg muscle strength and innervation for alternating right and left movement of the arms and legs, immaturity in coordinated movement between the arms, trunk and legs, and low instantaneous muscle strength of the arms.
\end{abstract}

\section{Keywords:}

age-related change, declining physical fitness in children, wavelet interpolation method

JEL Classification: 100, I10, I19 